\title{
Mechanical response of a Laser Cladding repaired struc- ture: localization of plastic strain due to microstructure gradient
}

\author{
Camille Guévenoux ${ }^{1,2, *}$, Simon Hallais ${ }^{1}$, Alexandre Charles $^{2}$, Eric Charkaluk ${ }^{1}$, and Andrei \\ Constantinescu ${ }^{1}$ \\ ${ }^{1}$ Laboratoire de Mécanique des Solides, École Polytechnique, CNRS, 91128 Palaiseau Cedex, France \\ ${ }^{2}$ Computational Solid Mechanics, Safran Tech, 78114 Magny-les-Hameaux, France
}

\begin{abstract}
Laser Cladding is an additive manufacturing technology enabling to repair complex metallic components by removing the worn region and reconstructing locally the initial geometry. The aim of this work is to study the mechanical response of Inconel 718 repaired thin walls. More precisely, we perform an EBSD imaging and in-situ SEM tensile tests on specimen whose gauge section contains the interface between base material and repaired area. We observe the multiaxial strain patterns until failure at the grain level using a Digital Image Correlation method and superpose this pattern with the microstructure gradient induced by repair. The observations highlight a strain localization phenomenon in repaired structures mainly due to grain size effect.
\end{abstract}

\section{Introduction}

Repairing massive metallic components has become a major asset for industries [27] as a consequence of the high cost of technological alloys and of components manufacturing. Laser Cladding, also denoted as Direct Energy Deposition or Laser Metal Deposition, is an additive manufacturing process that involves a nozzle consisting of a coaxial laser beam and metallic powder jet. Compared to powder-bed additive manufacturing processes, it allows to add material on an existing piece and can then be used to add new features or to repair a component. Laser Cladding is a highly promising technology, by virtue of a small Heat Affected Zone (HAZ), when compared with other repair processes such as Tungsten Inert Gas or Gas Metal Arc Welding [5, 10].

The microstructure obtained with Laser Cladding is really specific and different from those created with more conventional processes like forge or foundry. The material experiences a first solidification with the displacement of the melt pool together with the laser but it can be remelted when the above layer is built. It is then annealed as the part stays at high temperatures until the end of the process $[17,28]$ what can lead to metallurgical transformations.

The thermal history of the process which controls the final microstructure is influenced by many process parameters that have been widely investigated in the literature. Among many articles, one can mention the following ones focusing on the impact of laser speed, laser

\footnotetext{
*e-mail: camille.guevenoux@ @ polytechnique.edu
} 
power and powder flow rate $[18,19]$, linear energy input (laser power divided by laser speed) $[26,30]$, lasing strategy $[11,16,19]$, inter-layer dwell time $[6,14,15]$.

In repaired components, an interface is created between the substrate and the cladded zone. The microstructure gradient, the depth of Heat Affected Zone are once again driven by the thermal history. This interface needs to be particularly looked at to ensure cohesion between the added material and the original part and thereafter to assess for the lifetime of the repaired component. In the literature, many design of repaired samples can be found with which the authors investigate the microstructure gradient at the interface, the global mechanical behavior (yield stress, ultimate tensile stress, ductility) or the failure location $[2,3,10,13,20,22-24,32]$.

The development of Digital Image Correlation (DIC) techniques [8] enables to build strain maps from in-situ observations acquired during mechanical tests. In [31], tensile tests conducted with DIC at a macroscopic level underlines the fact that the existence of a microstructure gradient induces strain localization. Otherwise, other works use DIC at a smaller scale to highlight spatial distribution of strain within grains $[4,7,9,29]$. However, no study could be found where DIC is conducted at grain level in repaired microstructures. The aim of this work is therefore to study strain distribution in a presence of a microstructure gradient in order to understand where failure will occur on repaired components.

\section{Material and methods}

\subsection{Interface manufacturing}

The material used in this study is a nickel alloy, Inconel 718 [25]. The substrate is a plate of $1.6 \mathrm{~mm}$ thick made of wrought Inconel 718 on top of which a single-bead wall is deposited by Laser Cladding. The powder used for Laser Cladding is an Inconel 718 powder of diameter 45-105 microns, manufactured by gas atomization by ARCAM. The samples were manufactured on a Laser Cladding BeAM Mobile machine [1]. This machine is equipped a coaxial nozzle including a fiber laser offering a maximum power of $500 \mathrm{~W}$, a powder jet and a local argon inerting. No heat treatment was applied to the samples after Laser Cladding. The specimen were finally cut in the bi-material wall to load the interface in traction.

\subsection{EBSD analysis and In-situ tensile test}

The samples surface was mechanically polished up to 1 micron before being submitted to ion polishing in a Gatan PECS II. The Scanning Electron Microscope used in this study both for EBSD analysis and in-situ tensile tests was a FEI Quanta 600 FEG-ESEM. The EBSD maps were acquired thanks to the post-processing software HKL Channel 5. A gold grid with a 3-micron pitch was then deposited by electro-lithography on the specimen surface in the interface area. The tensile tests were displacement-controlled at $0.002 \mathrm{~mm} / \mathrm{s}$ and several loading steps with increasing amplitudes were applied. For each step, the sample is loaded until a chosen displacement and then unloaded and maintain at $20 \mathrm{~N}$ during the acquisition of the grid images for DIC to avoid creep.

The strain maps were obtained using the home-made DIC software $C M V$ [8] and were next superimposed on the microstructure images from the EBSD using a Matlab code. Image post-processing was then carried out to compute an average strain per grain which was then analysed according to the distance between each grain and the interface. 


\section{Results}

\subsection{Microstructure analysis}

The conducted EBSD analysis are displayed in Fig. 1. The substrate appears to be composed of small equiaxed grains randomly oriented (average size 20 microns). The cladded deposit however has a much more specific microstructure. The deposit material microstructure consists of very large columnar grains (up to $1 \mathrm{~mm}$ length for the larger ones whereas the layers are only $0.2 \mathrm{~mm}$ high) and the microstructure is very textured : almost all grains are oriented towards the building direction. The process layers are not visible in this map. One can also notice that there is a transition zone between the substrate and the cladded region composed of smaller columnar grains making a herringbone pattern following the layers. This microstructure is similar to the one observed in [19] for high-power process parameters.

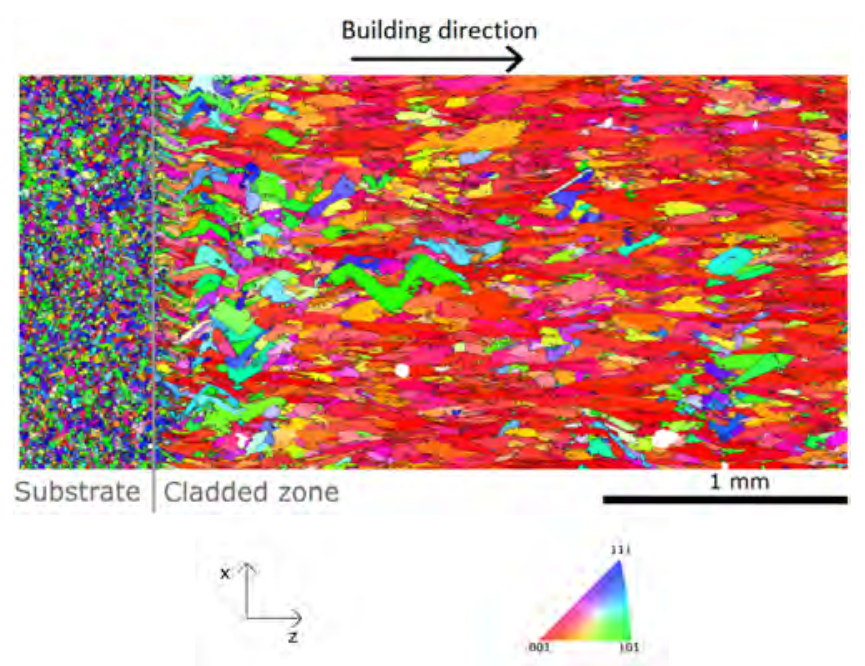

Fig. 1. Inverse pole figures along the building direction of the face view of repaired samples in the interface region.

\subsection{Strain maps}

When the tensile test is performed, plastic strain localization appears as the loading amplitude increases. The resulting strain component maps obtained by DIC are shown in Fig. 2 and reveals different aspects.

Firstly, despite the uniaxial loading of the sample, its mechanical response is locally multiaxial : the shear component of the strain tensor $\varepsilon_{x z}$ is non zero.

Furthermore, the strain state of the bi-material samples is not uniform : strain localization occurs at two length scales. First, the cladded region is much more deformed than the substrate, which is particularly visible on $\varepsilon_{z z}$ map. Then, in the repaired area, there is also a strain fluctuation at the grain size scale: strain varies within a grain or across a grain boundary. Two porosities can also be noticed in this region as exhibited in Fig. 2. They are both spherical and their dimension are respectively 40 and 60 microns. Spherical porosities which are common in additive manufactured material are due to gas trapped at solidification [19]. The strain pattern observed around them is similar to the characteristic strain distribution around a circular hole in traction. 


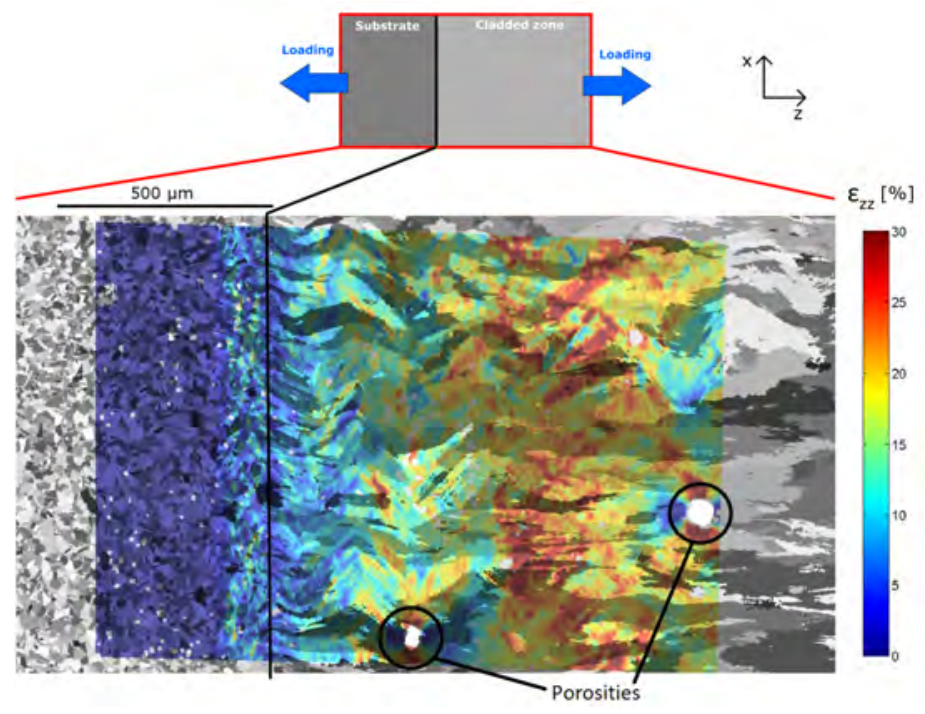

(a) Strain component $\varepsilon_{z z}$.

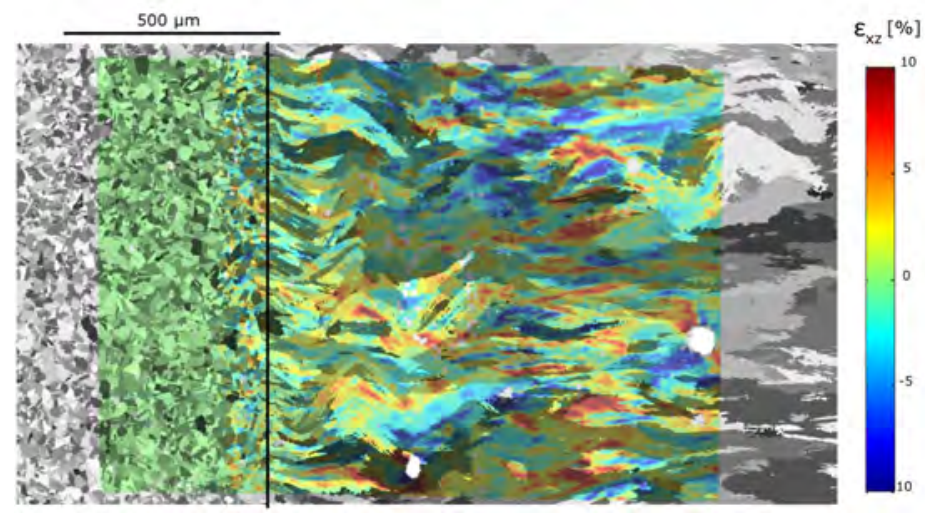

(b) Strain component $\varepsilon_{x z}$.

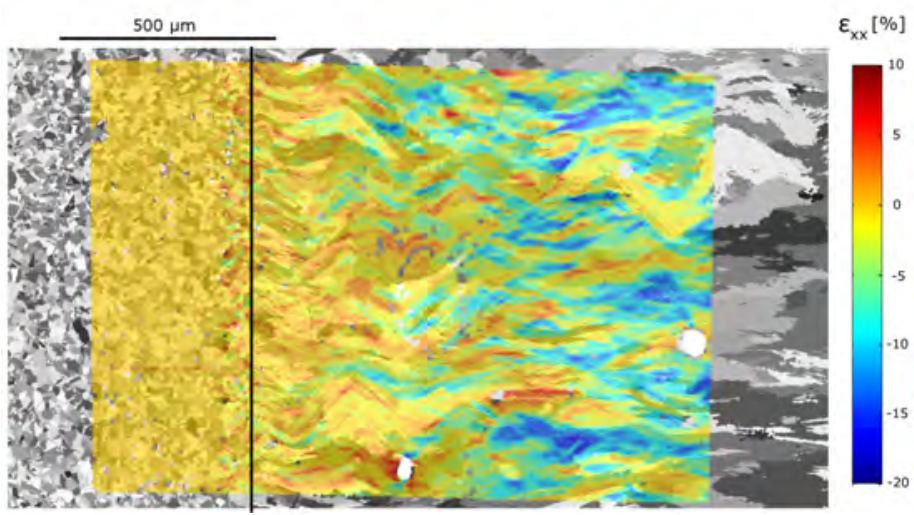

(c) Strain component $\varepsilon_{x x}$.

Fig. 2. Strain maps at the last step before failure where total elongation is $99 \%$ of failure elongation. 
(a)

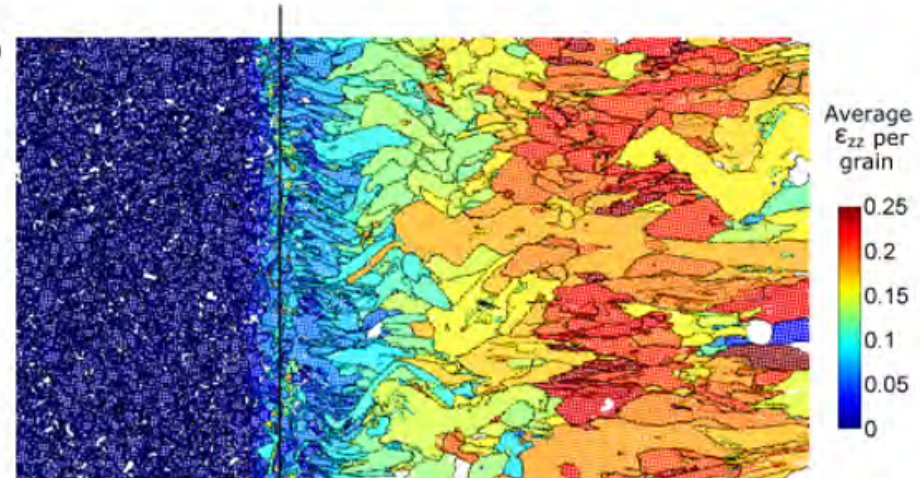

(b)

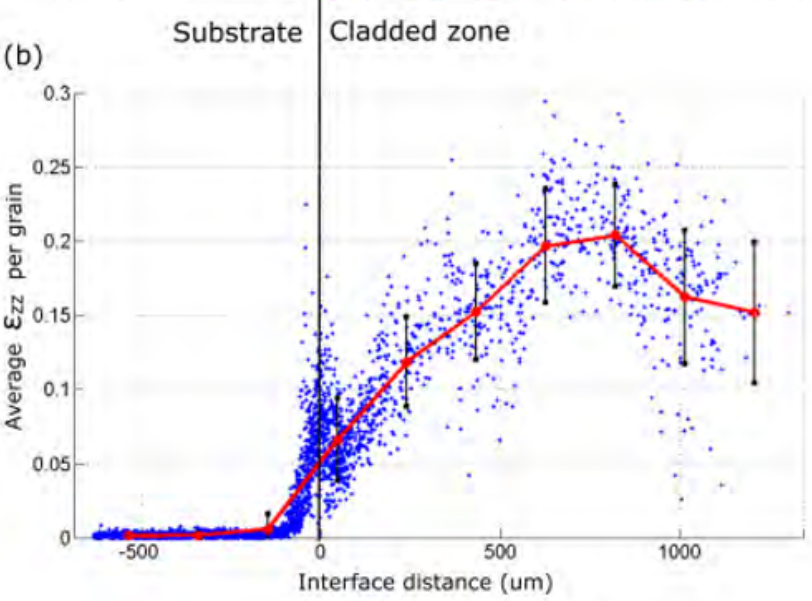

$\mathrm{h} !$

Fig. 3. Average value of $\varepsilon_{z z}$ per grain plotted (a) on the microstructure map ; (b) as a function of the distance between the grain centroid and the interface.

\subsection{Average grain strain}

From the strain values derived at each DIC point, it is then possible to compute the mean and standard deviation strains within one grain. This analysis reveals that except for the grains adjacent to a porosity, the strain is rather homogeneous within one grain. Fig. 3(a) displays an example of map of the microstructural response that can be reconstructed using average strain per grain.

Plotting the mean strain as a function of the distance between the grain centroids and the interface offers an interesting insight shown in Fig. 3(b). It confirms that plastic strains are much higher in the added material than in the original plate and enables to quantify the strain gradient.

\section{Discussion}

From the observations reported in the previous section, the following question arises: why does the cladded region deform more than the substrate? As the added material exhibits larger grains than the substrate and a very textured microstructure, two possible explanations have been investigated: orientation and grain size effect. 
The larger plastic strain in the cladded region could be explained by the fact that the dominant grain orientation is unfavorable to the activation of slip planes. However, the grains with the higher strain levels are not the one with the higher Schmid factor. Therefore, the orientation cannot be held responsible for strain localization.

The other rationale is that the main cause for strain distribution is a grain size effect. The dislocations involved in plasticity are stopped or slowed down by grain boundaries. In polycristals, this mechanism is referred to as the Hall-Petch effect [12,21]: the smaller the grains, the higher the yield stress. Our measurments outlined the correlation between the grain surface and their mean plastic strain, highlighting the fact that this strain spatial distribution is mainly driven by a grain size effect.

\section{Conclusion}

This work has highlighted that the components repaired using Laser Cladding exhibit a particular microstructure. In the interface region, the microstructure gradient is pronounced passing from the small equiaxed grains of the substrate to the large textured columnar grains. In-situ SEM uniaxial tensile tests have pointed out that this microstructure gradient induces a multiaxial heterogeneous mechanical response. Strain localization can be explained by grain size effect as the larger grains of the repaired area exhibits a lower yield stress.

In perspective we will explore the high cycle response of these microstructure and assess the fatigue lifetime of repaired components.

\section{References}

[1] BeAM. Gamme de machines - mobile et modulo. http://www.beam-machines.fr/fr/ produits, 2016.

[2] G. Bi and A. Gasser. Restoration of nickel-base turbine blade knife-edges with controlled laser aided additive manufacturing. Physics Procedia, 12:402 - 409, 2011. Lasers in Manufacturing 2011 - Proceedings of the Sixth International WLT Conference on Lasers in Manufacturing.

[3] P. Blackwell. The mechanical and microstructural characteristics of laser-deposited Inconel 718. Journal of Materials Processing Technology, 170(1):240 - 246, 2005.

[4] T. A. Book and M. D. Sangid. Strain localization in Ti-6Al-4V Widmanstätten microstructures produced by additive manufacturing. Materials Characterization, 122:104 $-112,2016$.

[5] T. DebRoy, H. Wei, J. Zuback, T. Mukherjee, J. Elmer, J. Milewski, A. Beese, A. Wilson-Heid, A. De, and W. Zhang. Additive manufacturing of metallic components - process, structure and properties. Progress in Materials Science, 92:112 - 224, 2018.

[6] E. R. Denlinger, J. C. Heigel, P. Michaleris, and T. Palmer. Effect of inter-layer dwell time on distortion and residual stress in additive manufacturing of titanium and nickel alloys. Journal of Materials Processing Technology, 215:123 - 131, 2015.

[7] J. M. Djouda, Y. Madi, F. Gaslain, J. Beal, J. Crépin, G. Montay, L. L. Joncour, N. Recho, B. Panicaud, and T. Maurer. Investigation of nanoscale strains at the austenitic stainless steel 316L surface: Coupling between nanogauges gratings and EBSD technique during in situ tensile test. Materials Science and Engineering: A, 740-741:315 $335,2019$. 
[8] P. Doumalin and M. Bornert. Micromechanical Applications of Digital Image Correlation Techniques, chapter Speckle Photography: Image Correlation Techniques, pages 67-74. Springer Berlin Heidelberg, Berlin, Heidelberg, 2000.

[9] D. Foehring, H. B. Chew, and J. Lambros. Characterizing the tensile behavior of additively manufactured Ti-6Al-4V using multiscale digital image correlation. Materials Science and Engineering: A, 724:536 - 546, 2018.

[10] B. Graf, A. Gumenyuk, and M. Rethmeier. Laser metal deposition as repair technology for stainless steel and titanium alloys. Physics Procedia, 39:376 - 381, 2012. Laser Assisted Net shape Engineering 7 (LANE 2012).

[11] J. M. H. L. Wei and T. DebRoy. Evolution of solidification texture during additive manufacturing. Nature, 2015.

[12] E. O. Hall. The deformation and ageing of mild steel: III discussion of results. Proceedings of the Physical Society. Section B, 64(9):747-753, sep 1951.

[13] B. He, X.-J. Tian, X. Cheng, J. Li, and H.-M. Wang. Effect of weld repair on microstructure and mechanical properties of laser additive manufactured Ti-55511 alloy. Materials $\mathcal{G}$ Design, 119:437 - 445, 2017.

[14] J. Heigel, P. Michaleris, and E. Reutzel. Thermo-mechanical model development and validation of directed energy deposition additive manufacturing of Ti-6Al-4V. Additive Manufacturing, 5:9 - 19, 2015.

[15] N. A. Kistler, D. J. Corbin, A. R. Nassar, E. W. Reutzel, and A. M. Beese. Effect of processing conditions on the microstructure, porosity, and mechanical properties of Ti6Al-4V repair fabricated by directed energy deposition. Journal of Materials Processing Technology, 264:172 - 181, 2019.

[16] C. Körner, H. Helmer, A. Bauereiß, and R. Singer. Tailoring the grain structure of IN718 during selective electron beam melting. MATEC Web of Conferences, 14:08001, 012014.

[17] Y. Lei, J. Xiong, and R. Li. Effect of inter layer idle time on thermal behavior for multi-layer single-pass thin-walled parts in GMAW-based additive manufacturing. The International Journal of Advanced Manufacturing Technology, 96(1):1355-1365, Apr 2018.

[18] V. Ocelík, I. Furár, and J. D. Hosson. Microstructure and properties of laser clad coatings studied by orientation imaging microscopy. Acta Materialia, 58(20):6763 - 6772, 2010.

[19] L. L. Parimi, R. G. A., D. Clark, and M. M. Attallah. Microstructural and texture development in direct laser fabricated Inconel 718. Materials Characterization, 89:102 $-111,2014$.

[20] H. Paydas, A. Mertens, R. Carrus, J. Lecomte-Beckers, and J. T. Tchuindjang. Laser cladding as repair technology for Ti-6Al-4V alloy: Influence of building strategy on microstructure and hardness. Materials $\mathcal{E}$ Design, 85:497 - 510, 2015.

[21] N. Petch. The cleavage strength of polycrystals. J. Iron Steel Inst., 174:25, 1953.

[22] R. Raju, M. Duraiselvam, V. Petley, S. Verma, and R. Rajendran. Microstructural and mechanical characterization of Ti6Al4V refurbished parts obtained by laser metal deposition. Materials Science and Engineering: A, 643:64 - 71, 2015.

[23] J. Song, Q. Deng, C. Chen, D. Hu, and Y. Li. Rebuilding of metal components with laser cladding forming. Applied Surface Science, 252(22):7934 - 7940, 2006.

[24] L. Song, G. Zeng, H. Xiao, X. Xiao, and S. Li. Repair of 304 stainless steel by laser cladding with $316 \mathrm{~L}$ stainless steel powders followed by laser surface alloying with WC powders. Journal of Manufacturing Processes, 24:116 - 124, 2016. 
[25] Special Metals. Inconel alloy 718, 2018.

[26] Z. Wang, T. A. Palmer, and A. M. Beese. Effect of processing parameters on microstructure and tensile properties of austenitic stainless steel 304L made by directed energy deposition additive manufacturing. Acta Materialia, 110:226 - 235, 2016.

[27] J. M. Wilson, C. Piya, Y. C. Shin, F. Zhao, and K. Ramani. Remanufacturing of turbine blades by laser direct deposition with its energy and environmental impact analysis. Journal of Cleaner Production, 80:170 - 178, 2014.

[28] Y. Yang, M. Knol, F. van Keulen, and C. Ayas. A semi-analytical thermal modelling approach for selective laser melting. Additive Manufacturing, 21:284 - 297, 2018.

[29] Y. S. J. Yoo, T. A. Book, M. D. Sangid, and J. Kacher. Identifying strain localization and dislocation processes in fatigued Inconel 718 manufactured from selective laser melting. Materials Science and Engineering: A, 724:444 - 451, 2018.

[30] K. Yuan, W. Guo, P. Li, J. Wang, Y. Su, X. Lin, and Y. Li. Influence of process parameters and heat treatments on the microstructures and dynamic mechanical behaviors of Inconel 718 superalloy manufactured by laser metal deposition. Materials Science and Engineering: A, 721:215 - 225, 2018.

[31] Z. Zhao, J. Chen, Q. Zhang, H. Tan, X. Lin, and W. dong Huang. Microstructure and mechanical properties of laser additive repaired Ti17 titanium alloy. Transactions of Nonferrous Metals Society of China, 27(12):2613 - 2621, 2017.

[32] Y. Zhu, J. Li, X. Tian, H. Wang, and D. Liu. Microstructure and mechanical properties of hybrid fabricated $\mathrm{Ti}-6.5 \mathrm{Al}-3.5 \mathrm{Mo}-1.5 \mathrm{Zr}-0.3 \mathrm{Si}$ titanium alloy by laser additive manufacturing. Materials Science and Engineering: A, 607:427 - 434, 2014. 